\title{
Twin-twin transfusion syndrome: neurodevelopmental screening test
}

\author{
Síndrome de transfusão feto-fetal: teste de triagem do desenvolvimento neurológico \\ Amabile Vessoni Arias', Denise Campos' ${ }^{1}$, Thatiane Moura Campos-Zanelli', Daniela Silva de Souza ${ }^{1}$, \\ Cleisson Fabio Andrioli Peralta ${ }^{2}$, Marilisa Mantovani Guerreiro ${ }^{1}$
}

\begin{abstract}
Objective: To assess the neurodevelopmental functions (cognition, language and motor function) of survivors of twin-twin transfusion syndrome (TTTS). Method: Observational cross-sectional study of a total of 67 monochorionic diamniotic twins who underwent fetoscopic laser coagulation (FLC) for treatment of TTTS. The study was conducted at the Center for Investigation in Pediatrics (CIPED), Universidade Estadual de Campinas. Ages ranged from one month and four days to two years four months. Bayley Scales of Infant and Toddler Development Screening Test-III, were used for evaluation. Results: Most children reached the competent category and were classified as having appropriate performance. The preterm children scored worse than term infants for gross motor subtest ( $p=0.036)$. Conclusion: The majority of children reached the expected development according to their age. Despite the good neurodevelopment, children classified at risk should be monitored for development throughout childhood.
\end{abstract}

Keywords: child, child development, diseases in twins, fetofetal transfusion.

RESUMO

Objetivo: Avaliar as funções do desenvolvimento neurológico (cognição, linguagem e motricidade) de sobreviventes da síndrome de transfusão feto-fetal (STFF). Método: Estudo transversal observacional, total de 67 gêmeos diamnióticos monocoriônicos submetidos à coagulação a laser por fetoscopia para o tratamento da STFF. O estudo foi realizado no Centro de Investigação em Pediatria (CIPED), Universidade Estadual de Campinas. A idade variou entre um mês e quatro dias a dois anos e quatro meses. Foram utilizadas as Bayley Scales of Infant and Toddler Development Screening Test-III para avaliação. Resultados: A maioria das crianças atingiu a categoria competente e foi classificada como tendo desempenho adequado. As crianças prematuras obtiveram desempenho inferior quando comparadas às nascidas a termo no subteste motor global $(p=0,036)$. Conclusão: A maioria das crianças alcançou o desenvolvimento esperado de acordo para idade. Apesar do bom desenvolvimento neurológico, crianças classificadas na categoria de risco devem ser monitoradas para o desenvolvimento, durante a infância.

Palavras-chave: criança, desenvolvimento infantil, doenças em gêmeos, transfusão feto-fetal.

Twin-twin transfusion syndrome (TTTS) occurs in approximately $10 \%-15 \%$ of all monochorionic diamniotic twin pregnancies, develops typically between 15 and 26 weeks of gestation and is associated with a high perinatal morbidity and mortality ${ }^{1,2,3}$.

The pathophysiology of TTTS is an unbalanced transfusion of blood across placental vascular anastomoses from one twin (donor) to the other (recipient). Twin-twin transfusion syndrome results in a volume-depleted donor twin with signs of oliguria and oligo/anhydramnios and a volumeoverloaded recipient twin with polyuria and polyhydramnios, which may lead to impairment of various organ systems in both affected twins ${ }^{4}$.

Serial amnioreduction and fetoscopic laser coagulation (FLC) of placental anastomoses are the two main treatment options in chronic TTTS. According to a Cochrane systematic review, FLC results in higher survival rates and better neonatal outcomes than amnioreduction, and more babies were alive without neurological abnormality at the age of six months in the laser group than in the amnioreduction group (52\% vs. $31 \%)^{5}$.

Nonetheless, the incidence of severe neurological morbidity remains high in survivors of TTTS treated by FLC, ranging

\footnotetext{
${ }^{1}$ Universidade Estadual de Campinas, Departamento de Neurologia, Centro de Investigação em Pediatria, Campinas SP, Brazil;

${ }^{2}$ Universidade Estadual de Campinas, Departamento de Obstetrícia e Ginecologia, Hospital da Mulher Prof. Dr. José Aristodemo Pinotti, Sao Paulo SP, Brazil. Correspondente: Amabile Vessoni Arias; Universidade Estadual de Campinas, Departamento de Neurologia, Centro de Investigação em Pediatria; Rua Tessália Vieira de Camargo, 126; 13083-887 Campinas SP, Brasil; E-mail: amabilevessoni@gmail.com

Conflict of interest: There is no conflict of interest to declare.

Received 06 September 2014; Received in final form 17 November 2014; Accepted 08 December 2014
} 
from an estimated $6 \%$ to $18 \%$ of cases. Cerebral injury in TTTS treated with laser surgery is not fully prevented. Periventricular hemorrhagic infarction, and ischemic white matter damage have been detected antenatally in fetuses treated with laser therapy for TTTS ${ }^{6}$. The incidence of cerebral damage may be underestimated because neurodevelopmental impairments and intellectual disability may manifest several months or years after birth ${ }^{6}$.

The risk factors for the TTTS group are early gestational age (GA) at delivery, advanced Quintero stage, late GA at operation, the higher incidence of prematurity and low birth weight $t^{4,6,7}$. Multiple risk factors increase the risk of developmental disability, by either additive or multiplicative effects. All children should have their development monitored during infancy and childhood because of a baseline incidence of neurodevelopmental disability.

Clearly, the TTTS group requires careful screening and assessment for neurological development. Due to uncertainty about the long-term neurological and cognitive development after laser treatment for TTTS, some authors suggest that children should be examined at two years, and that the next appropriate time point is the beginning of school age around six years ${ }^{3}$. With higher survival rates, an increasing number of follow-up studies in TTTS survivors are being published, shedding more light on long-term neurodevelopmental outcome ${ }^{2}$.

Due to this uncertainty about the neurological development of children after laser treatment, the primary aim of this study was to assess survivors of TTTS with neurodevelopmental scales that evaluate cognition, language and motor functioning.

\section{METHOD}

The research design consisted of an observational crosssectional study that included monochorionic diamniotic twins who underwent FLC for treatment of TTTS. The total number of pregnancies that were treated was 41 (82 twin children) and we investigated 67 surviving children (81.70\%). The mortality rate was 15 (18.30\%), which occurred in the fetal and neonatal period. All families invited agreed to participate and signed the consent form. After data collection, there was no waiver by any family.

This project was approved by the Research Ethics Committee of the Medical School of the State University of Campinas (UNICAMP) (process no. 899/2011).

Children were selected using the following inclusion criteria: (i) children from monochorionic diamniotic twin pregnancies who had TTTS (stages I, II, III and IV according to the classification of Quintero et al. 1999) ${ }^{8}$ and underwent FLC; (ii) parents agreed to sign the informed consent; and (iii) children who were between one month and 42 months of age. An exclusion criterium was the presence of any other malformation unrelated to TTTS.

All FLC procedures were performed by the same surgeon (CFAP, who has seven years of experience in fetoscopic laser surgeries) at the Professor José Aristodemo Pinotti Hospital, from 2009 to 2012, according to the following technique: the placenta's chorionic plate vessels of the recipient fetus were initially mapped endoscopically through the amniotic cavity; the vascular equator (where most of the arterio-venous anastomoses are expected to be) was identified; a line of ablation of the chorionic plate was performed from one edge of the placenta to the other, including the arterio-venous anastomoses and vessels with unknown courses. Caution was taken to preserve the vessels originating from and returning to the same fetus, which were surrounded by this line of ablation. At the end of the photocoagulation process, polyhydramnios was drained through the fetoscopy sheath so that the deepest amniotic fluid pocket was less than $8 \mathrm{~cm}$ deep.

Development was assessed using the Bayley Scales of Infant and Toddler Development Screening Test, third edition ${ }^{9}$, which included 33 items for testing cognition, 24 items for receptive communication, 24 items for expressive communication, 27 items for fine motor skills and 26 items for gross motor skills. These items can be administered in children aged one to 42 months.

Each subtest (cognition, receptive language, expressive language, gross motor and fine motor skills) has a starting point consistent with the age or adjusted to the child's age. Every child is given an item score of zero or one. A zero score (0) refers to a child who did not carry out the item or failed to meet the criteria established by test. The score of one (1) refers to a child who met criteria established by test, showing adequate performance on the item.

To start the test, the child is required to achieve a score of one (1) on the first item of his/her starting point previously determined by chronological age or adjusted. The reversal rule is applied when the child is given zero (0) in the first item, requiring the examiner to revert to the previous starting point. The test is completed when the child receives four consecutive zeros.

At the end of the assessment a raw score is obtained for each subtest, which classifies children into three categories: competent (low risk for delay), emerging (requires subsequent reviews) and risk (should be referred for diagnostic assessment). To perform statistical analyses, the three categories of the Bayley Scale were grouped into two types of responses: appropriate responses (consisting of the competent category), and inadequate responses (comprising emerging and risk categories). Any suspicious behavior would place the child in the inadequate response group; therefore, the appropriate response group comprised children with reliable development what strengthened our data. 
Neurological examination was performed by a pediatric neurologist following our standard protocol ${ }^{10}$.

A normal neurological pattern was recorded when the child had normal execution of the tests, and amended when any evidence of abnormality was detected.

The infants were assessed at the CIPED of Universidade Estadual de Campinas from July, 2011 to July, 2013. The testing room was quiet, well lit, well ventilated, without bright or colorful pictures and free of distraction ${ }^{9}$. All infants were assessed in the presence of their mothers during intervals between feeds, when infants were alert and cooperative. The infants were evaluated only once.

Examinations were performed by an examiner and simultaneously monitored by one observer. The testers included a developmental neurologist and three physiotherapists, all members of the Interdisciplinary Group for Infant Development Evaluation (GIADI).

Infants who presented with developmental changes were referred for diagnostic confirmation, and then, if necessary, referred to a program for habilitation.

Statistical analyses were performed using the Statistical Package for Social Sciences for Personal Computer (SPSS/PC 16.0). The $\alpha$ level adopted for rejection of the null hypothesis was less than 0.05. The data were presented using frequencies for categorical variables. The comparison between cognitive, communication, motor performance and neurological evaluation, in each assessment (starting point), was investigated with the Fisher's Exact Test and Chi-Square Test. We used a significance level of $\mathrm{p}<0.05$.

\section{RESULTS}

We present an observational cross-sectional study of 67 twins who were survivors of TTTS after prenatal treatment by FLC. The age range of the children in the study was one month and four days to two years four months, taking into consideration the adjusted age.

In our study, 10 of the 67 children (14.92\%) had at least one classification at risk for any of the Bayley Scale subtests (cognitive, receptive communication, expressive communication, fine motor, gross motor). On the Bayley Scales, the risk classification indicates that the child should be referred for diagnostic assessment.

The descriptive analysis of sample characteristics of the TTTS and birth is presented in Table 1. Most of the children were female $(61.2 \%)$, were recipients $(56.9 \%)$, were severe by Quintero classification (stages II, III and IV) (89.6\%), were appropriate for gestational age $(68.7 \%)$, were preterm (89.6\%), and had Apgar scores at 1 minute $\geq 7(73.1 \%)$ and 5 minutes $\geq 7$ (69.6\%).

The mean birth weight was 1.697g [0.470-3.300] and the mean gestational age was 32.5 weeks [26.4-37.6]. Following the Quintero classification, we found stage I consisted of seven children (10.45\%), stage II of 16 (23.88\%), stage III of $28(41.79 \%)$ and stage IV of $16(23.88 \%)$.

The outcomes of classification according to the Bayley scale subtests are listed in Table 2. For all subtests assessed (cognitive, receptive and expressive communication, fine and gross motor) the majority of children reached the competent category, followed by those in the emerging category and the minority of all children remained in the at-risk category. Until this point, normal neurological development had been observed in most of the children.

The classification according to appropriate or inadequate performances is listed in Table 3. The trend in the classification of normality is observed again, as most of the children were classified as appropriate for development.

In Table 4, all subscales of the Bayley and neurological examination were statistically evaluated for the variables

Table 1. Clinical characteristics of all Twin-twin transfusion syndrome (TTTS) cases before FLC (N=67).

\begin{tabular}{|c|c|c|c|}
\hline Gender & $\begin{array}{c}F \\
41(61.2)\end{array}$ & $\begin{array}{c}M \\
26(38.8)\end{array}$ & $\begin{array}{c}\text { Total } \\
67(100.0)\end{array}$ \\
\hline Donor/Recipients & D & $\mathrm{R}$ & \\
\hline & $28(43.1)$ & 37 (56.9) & $65^{\star}(100.0)$ \\
\hline Quintero Stage & $\begin{array}{l}\text { II, III, IV } \\
60 \text { (89.6) }\end{array}$ & $\begin{array}{c}\text { I } \\
7(10.4)\end{array}$ & $67(100.0)$ \\
\hline Fetal Growth & $\begin{array}{c}\text { SGA } \\
21(31.3)\end{array}$ & $\begin{array}{c}\text { AGA } \\
46(68.7)\end{array}$ & $67(100.0)$ \\
\hline Gestational Age & $\begin{array}{l}\text { Preterm } \\
60 \text { (89.6) }\end{array}$ & $\begin{array}{c}\text { Term } \\
7(10.4)\end{array}$ & $67(100.0)$ \\
\hline Apgar Score - $1^{\text {st }}$ & $\begin{array}{c}<7 \\
7(10.4)\end{array}$ & $\begin{array}{c}\geq 7 \\
49(73.1)\end{array}$ & $56 * *(100.0)$ \\
\hline Apgar Score $-5^{\text {th }}$ & $\begin{array}{c}<7 \\
2(3.4)\end{array}$ & $\begin{array}{c}\geq 7 \\
56(69.6)\end{array}$ & $58 * \star \star(100.0)$ \\
\hline
\end{tabular}

FLC: Fetoscopic laser coagulation; F: Female; M: Male; D: Donor; R: Recipients; Quintero Stage (II-IV: severe; I: mild); Fetal Growth (SGA: small for

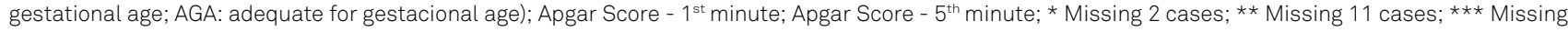
9 cases. 
Table 2. Classification according to the Bayley scale subtests $(N=67)$.

\begin{tabular}{lccc}
\hline & & Categories & \\
\cline { 2 - 4 } Subtests & Competent & $f(\%)$ & Emerging \\
& $5(\%)$ & $13(19.4)$ & $4(6.0)$ \\
Cognitive & $50(74.6)$ & $10(14.9)$ & $2(3.0)$ \\
Receptive Communication & $55(82.1)$ & $24(35.8)$ & $3(4.5)$ \\
Expressive Communication & $40(59.7)$ & $18(26.9)$ & $4(6.0)$ \\
Fine Motor & $45(67.2)$ & $23(34.3)$ & $4(6.0)$ \\
Gross Motor & $40(59.7)$ & & \\
\hline
\end{tabular}

f: Frequency; \%: Percentage.

gender (female/male), donor/recipient, ranking in Quintero stages, classification of fetal growth (appropriate for GA and small for GA), classification of GA at birth (preterm/ term) and the Apgar score for the $1^{\text {st }}$ and $5^{\text {th }}$ minutes. Our data showed no significant differences differences with respect to the variables evaluated: cognition, receptive communication, expressive communication, fine and gross motor function and neurological examination.

Our results demonstrated a single statistically significant difference $(p=0.036)$ in the gross motor subtest. We found a significantly higher rate of term children with adequate performance $(100.0 \%)$ when compared to preterm infants who scored adequately (55\%).

Most of our children were premature. The minimum GA was 26 weeks and four days, the average was 32 weeks and five days, and maximum was 37 weeks and six days. Three children $(4.47 \%)$ were extremely premature infants (GA less than 28 weeks); 37 children (55.22\%) were moderately preterm infants (28-33 weeks of GA); and, 20 children $(29.85 \%)$ were late preterm infants. Only seven children (10.45\%) were born at term.

Sixty-three patients (94.03\%) underwent neurological examination, which revealed nine children with strabismus (14.28\%), two children with microcephaly (3.17\%), one child with obstetric brachial plexus injury (1.58\%), and four children with spastic cerebral palsy (5.97\%), three of them with tetraparesis and one with hemiparesis. Neurological evaluation could not be performed in four patients $(5.97 \%)$. These children could not be examined due to tiredness.

Table 3. Classification according to appropriate or inadequate performances $(N=67)$.

\begin{tabular}{lcc}
\hline \multirow{2}{*}{ Subtests } & \multicolumn{2}{c}{ Performances } \\
\cline { 2 - 3 } & $\begin{array}{c}\text { Appropriate } \\
f(\%)\end{array}$ & $\begin{array}{c}\text { Inadequate } \\
f(\%)\end{array}$ \\
\hline Cognitive & $50(74.6)$ & $17(25.4)$ \\
Receptive Communication & $55(82.1)$ & $12(17.9)$ \\
Expressive Communication & $40(59.7)$ & $27(40.3)$ \\
Fine Motor & $45(67.2)$ & $22(32.8)$ \\
Gross Motor & $40(59.7)$ & $27(40.3)$ \\
\hline
\end{tabular}

f: Frequency; \%: Percentage.

\section{DISCUSSION}

The focus of this study was to assess survivors of TTTS with neurodevelopmental scales that evaluate cognition, language and motor functioning. Most children presented with adequate development for assessed age. They were classified in the competent category and reached appropriate performance in the five subtests of the Bayley Scales.

This study represents one of the few Brazilian studies addressing the neurological development of monochorionic diamniotic twins who underwent FLC for treatment of TTTS. The assessment tool utilized in this study is one of the most used in similar studies and has an overall acceptance; moreover, it was managed by an experienced team. All FLC procedures were performed by the same surgeon. We believe that the reasons above irrevocably strengthen our findings.

Our study has five limitations: (1) the sample was small, mainly because it is a rare syndrome, which made collecting data extremely laborious; (2) the age group distribution of the children evaluated in this research is extensive covering one month to 42 months of life. This fact must be especially because we are dealing with a rare syndrome that leads to preterm birth and its complications; (3) we performed a transversal assessment; (4) we may have missed some children with cerebral palsy, because it is very difficult to diagnose cerebral palsy in very young children; and (5) we used a non-standard assessment tool for the Brazilian population. There is a scarcity of assessment tools validated and standardized in Brazil. However, the Bayley Scales have an overall acceptance.

Our data suggest that FLC treatment was an effective procedure to allow normal development in most infants. Compared with other treatment options like serial amniocenteses, the FLC seems to achieve both higher survival rates and a lower rate of long-term morbidity, such as neurologic or developmental abnormality. Besides, it is well established that the amnioreduction is associated with an increased risk of severe cerebral injury compared to laser surgery in survivors of TTTS ${ }^{4,11,12}$. Therefore, laser treatment seems to be the treatment of choice, since the incidence of cerebral palsy in the group of survivors treated with 
Table 4. Outcomes for all Twin-twin transfusion syndrome (TTTS) cases treated by FLC ( $N=67)$.

\begin{tabular}{|c|c|c|c|c|c|c|}
\hline Variable & $\begin{array}{l}\text { Cognitive } \\
\text { (p-value) }\end{array}$ & $\begin{array}{l}\text { Receptive } \\
\text { Communication } \\
\text { (p-value) }\end{array}$ & $\begin{array}{c}\text { Expressive } \\
\text { Communication } \\
\text { (p-value) }\end{array}$ & $\begin{array}{c}\text { Fine Motor } \\
\text { (p-value) }\end{array}$ & $\begin{array}{l}\text { Gross Motor } \\
\text { (p-value) }\end{array}$ & $\begin{array}{c}\text { Neurological } \\
\text { Examination } \\
\text { (p-value) }\end{array}$ \\
\hline Gender (F / M) & $0.135^{\star}$ & $0.753+$ & $0.450^{*}$ & $0.774^{\star}$ & $0.075^{\star}$ & $0.564^{*}$ \\
\hline Donor/Recipients** (D / R) & $0.339 *$ & $0.068^{*}$ & $0.851^{*}$ & $0.295^{*}$ & $0.683^{*}$ & $0.631^{*}$ \\
\hline Quintero Stage (II-IV / I) & $0.063+$ & $0.600+$ & $1.000+$ & $0.206+$ & $0.427+$ & $0.690+$ \\
\hline Fetal Growth (SGA/ AGA) & $0.229+$ & $0.740+$ & $0.432^{\star}$ & $0.536^{*}$ & $0.773^{*}$ & $0.518^{*}$ \\
\hline Gestational Age (Preterm / Term) & $0.669+$ & $0.336+$ & $0.693+$ & $0.412+$ & $0.036+$ & $1.000+$ \\
\hline Apgar Score $-1^{\text {st } \star * \star}<7 / \geq 7$ & $0.184+$ & $0.966+$ & $0.234+$ & $0.177+$ & $0.629+$ & $0.393+$ \\
\hline Apgar Score $-5^{\text {th } * * * *}<7 / \geq 7$ & $1.000+$ & $0.318+$ & $0.521+$ & $0.127+$ & $0.169+$ & $1.000+$ \\
\hline
\end{tabular}

FLC: Fetoscopic laser coagulation; F: Female; M: Male; D: Donor; R: Recipients; Quintero Stage (II-IV: severe; I: mild); Fetal Growth (SGA: small for gestational age; AGA: adequate for gestacional age); Apgar Score - 1 $^{\text {st }}$ minute; Apgar Score $-5^{\text {th }}$ minute; + Fisher's Exact Test; * Chi-Square Test; ** Missing 2 cases; $* \star \star$ Missing 11 cases; $* * \star *$ Missing 9 cases.

amnioreduction series reached $26 \%^{7,6,13,14,15,16,17}$. However, special care should be taken when different studies are compared because discrepant results may partly be due to different methodology, selection criteria, and definitions of neurodevelopmental impairment ${ }^{12}$.

Our data showed that $14.92 \%$ of our children had at least one classification at risk for any of the Bayley Scale subtests. Our results are in keeping with other studies that found neurological impairment (minor or severe) ranging from $4.6 \%$ to $17 \%$ after FLC procedure $e^{6,711,12,13,16,17}$. Another interesting finding was that neurodevelopmental impairment occurred in $10 \%$ of monochorionic diamniotic twin pregnancies without $\mathrm{TTTS}^{18}$. This finding overlaps with our data suggesting that the FLC procedure only slightly increases the risk of a neurological complication and these infants need careful neurodevelopmental monitoring.

Our children were mostly female, recipients, classified in stages II, III and IV of the Quintero classification, were appropriate for GA, were preterm, and obtained Apgar scores of $\geq 7$ at the first minute and $\geq 7$ at five minutes. Risk factors for neurodevelopmental disability in survivors of TTTS treated with FLC are: low GA at birth; severity of disease assessed by Quintero classification (stages II, III and IV); low birthweight; and intrauterine growth restriction. It seems that low GA at birth is the major risk factor for adverse neurodevelopmental outcome. There is no increased risk between donors and recipients, either when the two siblings survived or when only one child survived ${ }^{1,2,3,11,12,19,20,21,22}$. Although our data showed significant prematurity (89.6\%) and advanced stages of Quintero (89.6\% in stage II, III, IV) as major points of concern, our children reached the expected responses and were classified mostly within the normal range of development.
When our children were compared for gender, donor/recipient, Quintero stages, classification of fetal growth, and Apgar score, we found no significant difference either for Bayley Scale subtests or for the neurological examination. However, when the children were divided into two groups according to GA, the preterm group showed lower performance on the gross motor subtest (55\% achieved the expected responses) than the term group (100\% achieved the expected responses). We also found four children in our cohort who could be diagnosed as having cerebral palsy.

It is quite clear that prematurity may correlate with

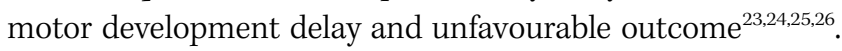
In keeping with our findings, another study ${ }^{27}$ utilized Alberta Infant Motor Scale and found gross motor deficits. This finding reinforces our data, since another developmental scale also demonstrated similar abnormality in preterm infants.

One of the important factors possibly influencing the motor development in preterm infants is the brain maturation process. It has been shown that premature birth has an influence on structural maturation manifested as a decrease in cortical and deep gray matter volume, smaller cerebral surface area, smaller cerebral volume, decreased myelinization, decreased gray and white matter differentiation, volume reduction in the cerebellum, corpus callosum, hippocampus, basal ganglia, thalami, and larger volume of the ventricles ${ }^{28,29,30}$.

In conclusion, despite the relatively good neurodevelopmental outcome in the present study, it is recommended that children classified in the category of emerging, and especially those classified at risk, should be monitored for development throughout childhood. By adopting this procedure, diagnosis and early intervention could occur if necessary. A better prognosis in childhood undoubtedly influences the quality of life in adolescence and adulthood.

References

1. Sutcliffe AG, Sebire NJ, Pigott AJ, Taylor B, Edwards PR, Nicolaides KH. Outcome for children born after in utero laser ablation therapy for severe twin-to-twin transfusion syndrome. BJOG. 2011;108(12):1246-50. http://dx.doi.org/10.1111/j.1471-0528.2001.00294.x 
2. Klink JM, Koopman HM, Oepkes D, Walther FJ, Lopriore E. Long-term neurodevelopmental outcome in monochorionic twins after fetal therapy. Early Hum Dev. 2011;87(9):601-6. http://dx.doi.org/10.1016/j. earlhumdev.2011.07.007

3. Graeve P, Banek C, Stegmann-Woessner G, Maschke C, Hecher K, Bartmann P. Neurodevelopmental outcome at 6 years of age after intrauterine laser therapy for twin-twin transfusion syndrome. Acta Paediatr; 2012;101(12):1200-5. http://dx.doi.org/10.1111/apa.12017

4. Maschke C, Diemert A, Hecher K, Bartmann P. Long-term outcome after intrauterine laser treatment for twin-twin transfusion syndrome. Prenat Diagn. 2011;31(7):647-53. http://dx.doi.org/10.1002/pd.2797

5. Roberts D, Gates S, Kilby M, Neilson JP. Interventions for twin-twin transfusion syndrome: a Cochrane review. Ultrasound Obstet Gynecol. 2008;31(6):701-11

6. Rossi AC, Vanderbilt D, Chmait RH. Neurodevelopmental outcomes after laser therapy for twin-twin transfusion syndrome: a systematic review and meta-analysis. Obstet Gynecol. 2011;118(5):1145-50. http://dx.doi.org/10.1097/AOG.0b013e318231827f

7. Chang YL, Chao AS, Chang SD, Lien R, Hsieh PC, Wang C. The neurological outcomes of surviving twins in severe twin-twin transfusion syndrome treated by fetoscopic laser photocoagulation at a newly established center. Prenat Diagn. 2012;32(9):893-6. http:// dx.doi.org/10.1002/pd.3929

8. Quintero RA, Morales WJ, Allen MH, Bornick PW, Johnson PK, Kruger M. Staging of twin-twin transfusion syndrome. J Perinatol. 1999;19(8):550-5. http://dx.doi.org/10.1038/sj.jp.7200292

9. Bayley N. Screening test of Bayley scales of infant and Toddler development-III. San Antonio: Pearson; 2006.

10. Diament A, Cypel S. Neurologia infantil. 4th ed. Rio de Janeiro: Atheneu; 2005.

11. Graef C, Ellenrieder B, Hecher K, Hackeloer BJ, Huber A, Bartmann P. Long-term neurodevelopmental outcome of 167 children after intrauterine laser treatment for severe twin-twin transfusion syndrome. Am J Obstet Gynecol. 2006;194(2):303-8. http://dx.doi.org/ 10.1016/j.ajog.2005.07.040

12. Lopriore E, Middeldorp JM, Sueters M, Oepkes D, Vandenbussche FP, Walther FJ. Long-term neurodevelopmental outcome in twin-to-twin transfusion syndrome treated with fetoscopic laser surgery. Am J Obstet Gynecol. 2007;196(3):231.e1-4. http://dx.doi.org/10.1016/j. ajog.2006.10.906

13. Banek CS, Hecher K, Hackeloer BJ, Bartmann P. Long-term neurodevelopmental outcome after intrauterine laser treatment for severe twin-twin transfusion syndrome. Am J Obstet Gynecol. 2003;188(4):876-80. http://dx.doi.org/10.1067/mob.2003.202

14. Lopriore E, Nagel HT, Vandenbussche FP, Walther FJ. Long-term neurodevelopmental outcome in twin-to-twin transfusion syndrome. Am J Obstet Gynecol. 2003;189(5):1314-9. http://dx.doi.org/10.1067/ S0002-9378(03)00760-9

15. Lopriore E; Sueters M; Middeldorp JM; Oepkes D; Vandenbussche FP; Walther FJ. Neonatal outcome in twin-to-twin transfusion syndrome treated with fetoscopic laser occlusion of vascular anastomoses. J Pediatr. 2005;147(5):597-602. http://dx.doi.org/ 10.1016/j.jpeds.2005.06.004

16. Wagner MM, Lopriore E, Klumper FJ, Oepkes D, Vandenbussche FP, Middeldorp JM. Short- and long-term outcome in stage 1 twin-totwin transfusion syndrome treated with laser surgery compared with conservative management. Am J Obstet Gynecol. 2009;201(3):86.e16. http://dx.doi.org/10.1016/j.ajog.2009.05.034

17. Lenclen R, Ciarlo G, Paupe A, Bussieres L, Ville Y. Neurodevelopmental outcome at 2 years in children born preterm treated by amnioreduction or fetoscopic laser surgery for twin-to-twin transfusion syndrome: comparison with dichorionic twins. Am J Obstet Gynecol. 2009;201(3):291.e1-5. http://dx.doi.org/10.1016/j. ajog.2009.05.036

18. Ortibus E, Lopriore E, Deprest J, Vandenbussche FP, Walther FJ, Diemert A, et al. The pregnancy and long-term neurodevelopmental outcome of monochorionic diamniotic twin gestations: a multicenter prospective cohort study from the first trimester onward. Am J Obstet Gynecol. 2009;200(5):494.e1-8. http://dx.doi.org/10.1016/j. ajog.2009.01.048

19. De Lia JE, Kuhlmann RS, Lopez KP. Treating previable twin-twin transfusion syndrome with fetoscopic laser surgery: outcomes following the learning curve. J Perinat Med. 1999;27(1):61-7. http:// dx.doi.org/10.1515/JPM.1999.007

20. Duncombe GJ, Dickinson JE, Evans SF. Perinatal characteristics and outcomes of pregnancies complicated by twin-twin transfusion syndrome. Obstet Gynecol. 2003;101(6):1190-6. http://dx.doi.org/ 10.1016/S0029-7844(03)00231-X

21. Peralta CF, Ishikawa LE, Bennini JR, Braga AFA, Rosa IRM, Biondi MC et al. Ablação dos vasos placentários com laser para tratamento da sindrome de transfusão feto-fetal grave: experiência de um centro universitário no Brasil. Rev Bras Ginecol Obstet. 2010;32(5):214-21. http://dx.doi.org/10.1590/S0100-72032010000500003

22. Vanderbilt DL, Schrager SM, Llanes A, Chmait RH. Revalence and risk factors of cerebral lesions in neonates after laser surgery for twintwin transfusion syndrome. Am J Obstet Gynecol. 2012;207(4):320. e1-6. http://dx.doi.org/10.1016/j.ajog.2012.06.031

23. Schlapbach LJ, Adams M, Proietti E, Aebischer M, Grunt S, BorradoriTolsa C et al. Outcome at two years of age in a Swiss national cohort of extremely preterm infants born between 2000 and 2008. BMC Pediatr. 2012;12(198):198. http://dx.doi.org/10.1186/1471-2431-12198

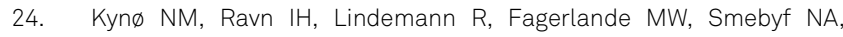
Torgersen AM. Effect of an early intervention programme on development of moderate and late preterm infants at 36 months: a randomized controlled study. Infant Behav Dev. 2012;35(4):916-26. http://dx.doi.org/10.1016/j.infbeh.2012.09.004

25. Yang $\mathrm{H}$, Einspieler $\mathrm{C}$, Shi $\mathrm{W}$, Marschik PB, Wang $\mathrm{Y}$, Cao $\mathrm{Y}$ et al. Cerebral palsy in children: movements and postures during early infancy, dependent on preterm vs. full term birth. Early Hum Dev. 2012;88(10):837-43. http://dx.doi.org/10.1016/j.earlhumdev.2012.06.004

26. Himpens, E, Van den Broeck C, Oostra A, Vanhaesebrouck P. Prevalence, type, distribution, and severity of cerebral palsy in relation to gestational age: a meta-analytic review. Dev Med Child Neuro. 2008;50(5):334-40. http://dx.doi.org/10.1111/j.1469-8749.2008.02047.x

27. Haastert IC, de Vries LS, Helders PJ, Jongmans MJ. Early gross motor development of preterm infants according to the Alberta Infant Motor Scale. J Pediatr. 2006;149(5):617-22. http://dx.doi.org/10.1016/j. jpeds.2006.07.025

28. Lind A, Parkkola R, Lehtonen L, Munck P, Maunu J; Lapinleimu H et al. Associations between regional brain volumes at term-equivalent age and development at 2 years of age in preterm children. Pediatr Radiol. 2011;41(8):953-61. http://dx.doi.org/10.1007/s00247-011-2071-x

29. Kieviet JF, Zoetebier L, Elburg RM, Vermeulen RJ, Osterlaan J. Brain development of very preterm and very low-birthweight children in childhood and adolescence: a meta-analysis. Dev Med Child Neurol. 2012;54(4):313-23. http://dx.doi.org/10.1111/j.1469-8749.2011.04216.x

30. de Vis JB, Petersen ET, Vries LS, Groenendaal F, Kersbergen KJ, Alderliesten $T$ et al. Regional changes in brain perfusion during brain maturation measured non-invasively with Arterial Spin Labeling MRI in neonates. Eur J Radiol. 2013;82(3):538-43. http://dx.doi.org/ 10.1016/j.ejrad.2012.10.013 